УДК 622.24 .06

\title{
ИССЛЕДОВАНИЕ БИОПОЛИМЕРНЫХ БУРОВЫХ РАСТВОРОВ НА ОСНОВЕ ВЫСОКОМИНЕРАЛИЗОВАННЫХ ПЛАСТОВЫХ ВОД ВОСТОЧНОЙ СИБИРИ
}

\author{
Буглов Николай Александрович¹, \\ bna@istu.edu
}

\author{
Аверкина Елена Владимировна1, \\ averkina.l@yandex.ru \\ Устюжанин Александр Олегович1, \\ al.ust7@yandex.ru
}

\author{
Красинская Анастасия Сергеевна², \\ krasinskaya_as@irkutskoil.ru \\ 1 Иркутский национальный исследовательский технический университет, \\ Россия, 664074, г. Иркутск, ул. Лермонтова, 83. \\ 2000 «ИНК-СЕРВИС», \\ Россия, 664007, г. Иркутск, ул. Октябрьской Революции, 24А.
}

\begin{abstract}
Актуальность исследования обусловлена необходимостью полезного использования попутно добываемых с нефртью пластовых вод в качестве основы для приготовления минерализованных соленасыщенных буровых растворов при бурении на месторождениях Восточной Сибири.

Цель: исследовать и предложить полимерные системы буровых растворов на основе пластовых вод Восточной Сибири.

Объекты: пластовая вода Даниловского и Ичединского нефртегазоконденсатных месторождений, рецептуры и компоненты современных систем полимерных буровых растворов.

Методы: инструментальные методы определения параметров буровых растворов по ГОСТ 33213-2014 и РД 39-00147001-773-2004 (фильтрационнье и реологические свойства); описание образцов, сравнение характеристик с растворами-аналогами. Результаты. Изучены и описаны фризико-химические характеристики пластовых вод; приготовлены полимерные системы буровых растворов на основе чистой и разбавленной пластовой вод; проведены сравнительные исследования приготовленных растворов с растворами, применяющимися в настоящее время при строительстве скважин в Восточной Сибири; представлена описательная характеристика растворов и выдвинуты теории по взаимодействию используемых реагентов $c$ пластовой водой. Установлено, что за счет высокого содержания хлоридов кальция и магния в пластовой воде процесс растворения полимерных реагентов может приостанавливаться, что приводит к полной потере всех вязкостных, фрильтрационных и реологических свойств буровых растворов; содержание в пластовой воде в достаточном количестве магния ( $\geq 10$ г/л) гарантирует получение гидрогель-магниевых буровых растворов; применение попутных пластовых вод позволит снизить материальные и временные затраты, связаннье с насыщением раствора на поверхности, одновременно предупредить кавернообразование и в значительной степени предотвратить растворимость соленосньх пород.
\end{abstract}

\section{Ключевые слова:}

Пластовая вода, гидроминеральное сырье, минерализащия, буровой раствор,

соленасыщенный буровой раствор, Ярактинское месторождение, промывочная жидкость, Восточная Сибирь.

\section{Введение}

Высокие темпы добычи углеводородного сырья приводят к неизбежному росту извлекаемой попутной пластовой воды. Обычно она занимает пониженные зоны продуктовых горизонтов, а в отдельных случаях может присутствовать как самостоятельная гидрогеологическая структура. Пластовая вода всегда содержится в скважинной продукции и в некоторых случаях может составлять даже 95-99 \% от ее объёма.

Состав пластовых вод зависит от геологического возраста и химических свойств вмещающих пород, а также углеводородного сырья. Поэтому они, как в пределах одной нефтяной или газовой залежи, так и для месторождений, имеют существенные различия в количественном содержании и химическом составе растворенных минеральных солей, газов и полезного ископаемого.

Изменяются характеристики пластовых вод и по мере разработки залежи, а также снижения давления, температуры и контакта с другими пластовыми водами. Все это происходит в процессе добычи нефти и приводит к дегазации и к нарушению ионных равновесий. Помимо макрокомпонентов, таких как $\mathrm{Na}, \mathrm{K}$, $\mathrm{Ca}, \mathrm{Mg}$, в пластовых водах присутствуют достаточно редкие микрокомпоненты $\mathrm{Sr}, \mathrm{Rb}, \mathrm{I}, \mathrm{Br}, \mathrm{Li}$ и другие.

Значительными запасами пластовых вод обладает Восточно-Сибирская артезианская область, в состав которой входит Ангаро-Ленский бассейн. Район данных гидрогеологических структур совмещен с нефтегазоносным комплексом Восточной Сибири, в частности, с месторождениями углеводородного сырья, такими как: Ярактинское, Верхнечонское, Ковыктинское, Даниловское, Марковское, Ичёдинское и др.

Осадочная толща в пределах месторождений довольно отчетливо представлена тремя гидрогеологическими формациями: подсолевой, соленосной (галогенной) и надсолевой. В их составе, по классифика- 
ции Е.В. Пиннекера, основанной на степени минерализации, можно выделить следующие типы подземных вод: слабые - до 150 г/л; крепкие - 150-320 г/л; весьма крепкие - 320-500 г/л, предельно насыщенные - более 500 г/л [1].

В последние годы вызывает большой практический интерес вопрос их широкого применения в производственных процессах нефтегазовых компаний. Использование попутно добываемых высокоминерализованных пластовых вод является весьма актуальным и перспективным для энергетической отрасли. В настоящее время они активно используются при закачивании в продуктивный горизонт с целью поддержания пластового давления, а также при консервации и глушении скважин. Кроме того, это гидроминеральное сырье может являться источником для извлечения ценных микрокомпонентов ( $\mathrm{Li}, \mathrm{Br}, \mathrm{I}$ и др.) [2], соли и рассматриваться в качестве основы для приготовления буровых растворов.

В настоящей статье мы обратим внимание на последнее предложение как одно из действительно перспективных решений в области промывки скважин в горно-геологических условиях нашего региона.

На месторождениях Восточной Сибири интервалы, перекрываемые технической и эксплуатационной колоннами, представлены хемогенными породами, встречающимися в виде пачек каменной соли с переслаиваниями доломитов, доломито-ангидритов и известняков.

Строительство скважин в соленосных отложениях часто обуславливается нарушением устойчивости ствола в виде каверн, сужений и сопровождается проработками, посадками, затяжками, прихватами инструмента, забуриванием нового ствола, а также повреждением обсадных колонн [3].

Для повышения устойчивости ствола скважины в указанных интервалах, а также исключения других возможных проблем в большинстве случаев применяют системы полимерных соленасыщенных промывочных жидкостей на базе рассолов натриевой, кальциевой и калийной солей $[4,5]$.

Основными преимуществами данных полимерных растворов являются способность полимеров связывать свободную воду своими длинными молекулами и образовывать водостойкую пленку на стенке скважины, что препятствует нарушению устойчивости ствола скважины в условиях бурения хемогенных пород. Также полимерные буровые растворы обеспечивают достаточно высокую выносную способность бурового раствора за счет тиксотропного восстановления структуры в режиме низких скоростей сдвига $[6,7]$.

В зависимости от горно-геологических условий состав и свойства технологических жидкостей подбираются индивидуально для каждого месторождения и скважины [8]. Для соленасыщенных буровых растворов дисперсионной средой является раствор на основе солей. В соответствии с содержанием солей, которые слагают разбуриваемые толщи, определяют состав и минерализацию раствора. Так, например, при бурении солевых структур в Восточной Сибири для основы промывочных жидкостей используют раствор $\mathrm{NaCl}$ с минерализацией 240-280 г/л.
Поэтому высокая минерализация пластовых вод создает предпосылки по целесообразности их использования в качестве основы буровых растворов для вскрытия соленосных отложений на месторождениях углеводородного сырья Восточной Сибири.

Основываясь на этом, авторами статьи была поставлена цель исследовать и разработать полимерные системы буровых растворов на основе пластовых вод Восточной Сибири. В данной публикации представлены описания и характеристики некоторых предложенных их составов, которые в дальнейшем позволят решать задачи по сокращению объемов дорогостоящих химических реагентов на заготовку промывочных жидкостей и получение более эффективной системы рецептур очистных агентов. С экономической точки зрения это не вызывает сомнения, так как применение указанных вод в качестве готовой основы для буровых растворов исключает необходимость закупки и транспортировки больших объемов технической соли на месторождения углеводородного сырья с тяжелой логистикой.

\section{Исследование буровых растворов}

В разные годы вопросами использования пластовых вод при создании различных по составу очистных агентов занимались Т.Д. Ланина, Д.А. Галян, Н.П. Чадина, И.М. Тимохин, В.В. Казанский, О.Б. Сукманский, О.А. Брагина, И.И. Климашкин, О.Л. Ангелопуло и др. Ими были предложены хлоркальциевые глинистые растворы [6, 9], растворы на основе гидрогеля магния $[6,9,10]$, безглинистые полимерсолевые растворы [11-13], реагенты для их стабилизации $[14,15]$ и утяжеленные растворы различной плотности [16], которые внедрялись на нефтегазовых месторождениях Республики Саха (Якутия), Пермского и Красноярского краев, Оренбургской и Иркутской областей.

В стороне от решения этого вопроса не остался и Иркутский национальный исследовательский технический университет (ИРНИТУ). Так, в 2003-2006 гг. на кафедре нефтегазового дела разрабатывались рецептуры гидрогельмагниевых растворов на основе рапы Знаменского месторождения, содержащей магний в количестве, необходимом для образования геля. Были получены промывочные жидкости, обладающие различной вязкостью, стабильностью показателей и низкими фильтрационными свойствами. Все они прошли успешную и многократную апробацию в Красноярском крае и Иркутской области при строительстве скважин в агрессивных условиях [17].

С 2018 г. сотрудниками кафедры нефтегазового дела ИРНИТУ, совместно со специалистами ООО «ИНК» и ООО «ИНК-Сервис» была поставлена задача по комплексному изучению и разработке рецептур промывочных жидкостей с использованием в качестве основы пластовых вод нефтегазовых месторождений Иркутской области.

Образцы изучаемой пластовой воды представляли собой попутные воды, отобранные с осинского продуктивного горизонта Ичёдинского нефтяного и с усольской свиты Даниловского нефегазоконденсатного месторождений. 
Таблица 1. Физико-химические характеристики пластовых вод

Table 1. Physical and chemical characteristics of reservoir waters

\begin{tabular}{|c|c|c|c|}
\hline \multirow[b]{2}{*}{$\begin{array}{l}\text { Определяемые показатели } \\
\text { Identifited properties }\end{array}$} & \multirow[b]{2}{*}{$\begin{array}{c}\text { Единицы } \\
\text { измерений } \\
\text { Units }\end{array}$} & \multicolumn{2}{|c|}{ Место отбора пробы/Sampling place } \\
\hline & & $\begin{array}{c}\text { Проба № } 1 \\
\text { Даниловское НГКМ } \\
\text { Sample no. 1 } \\
\text { Danilovskoe oil and gas condensate field }\end{array}$ & $\begin{array}{c}\text { Проба № } 2 \\
\text { Ичёдинское НM } \\
\text { Sample no. } 2 \\
\text { Ichedinskoe oil field }\end{array}$ \\
\hline Гидрокарбонат-ион/Bicarbonate ion & \multirow{10}{*}{$\begin{array}{l}\mathrm{M \Gamma} / \mathrm{dM}^{3} \\
\mathrm{mg} / \mathrm{dm}^{3}\end{array}$} & 815,0 & 284,3 \\
\hline Хлорид-ион/Chloride ion & & 402625 & 441250 \\
\hline Сульфат-ион/Sulfate ion & & $<0,5$ & $<0,5$ \\
\hline Натрий/Sodium & & 12750 & 4437 \\
\hline Калий/Potassium & & 19375 & 14162 \\
\hline Кальций/Calcium & & 21100 & 278875 \\
\hline Магний/Magnesium & & 12555 & 13212 \\
\hline Литий/Lithium & & 228 & 302,5 \\
\hline Стронций/Strontium & & 2450 & 3112 \\
\hline Минерализация/Mineralization & & 454400 & 474800 \\
\hline Водородный показатель/Hydrogen ion exponent & $\begin{array}{c}\text { ед. pH } \\
\text { pH units }\end{array}$ & 5,6 & 4,6 \\
\hline Плотность/Density & $\begin{array}{l}\mathrm{r} / \mathrm{cm}^{3} \\
\mathrm{~g} / \mathrm{cm}^{3}\end{array}$ & 1,31 & 1,36 \\
\hline
\end{tabular}

Согласно физико-химической характеристики (табл. 1), исследуемые воды относятся к хлориднокальциевому типу (по В.А. Сулину), имеют высокую минерализацию и плотность, а также низкие значения водородного показателя. Кроме этого, они содержат повышенные концентрации таких микрокомпонетов, как литий, бром, стронций, рубидий.

За основу проектируемой промывочной жидкости нами была принята рецептура соленасыщенного полимерного бурового раствора (СПБР) [18], используемая при бурении скважин в интервале технической и эксплуатационной колонн на Ярактинском нефтегазоконденсатном месторождении (НГКМ). Замеры его параметров производились согласно рекомендациям [19-21].

В соответствии с регламентом на заготовку и обработку базового очистного агента при строительстве скважин на Ярактинском НГКМ с плотностью $1,22 \ldots 1,25$ г/см ${ }^{3}$ последний имеет следующий состав $\left(\right.$ на $\left.1 \mathrm{~m}^{3}\right)$ : раствор хлорида натрия - 280 кг; кальцинированная сода $\mathrm{Na}_{2} \mathrm{CO}_{3}-2$ кг; каустическая сода $-0,5$ кг; крахмал - 20 кг; биополимер - 4 кг; полианионная целлюлоза высокой вязкости - 2,5 кг и полианионная целлюлоза низкой вязкости - 3 кг. В качестве биополимера использовалась ксантановая смола [22, 23].

Характеристики полимерной соленасыщенной промывочной жидкости: плотность $\rho=1,20 \ldots 1,25, \Gamma / \mathrm{cm}^{3}$, условная вязкость $\mathrm{YB}_{200 / 100}=45-50$ сек, водородный показатель $\mathrm{pH}=8-10$, пластическая вязкость ПВ $\leq 30$ мПа'с, динамическое напряжение сдвига ДНС $\geq 70$ дПа, статическое напряжение сдвига $\mathrm{CHC} \geq 24 / \geq 38$ дПа 10 сек/10 мин, фильтрация $\Phi_{30}$ API $\leq 4 \mathrm{~cm}^{3} / 30$ мин.

При проведении исследований авторами (табл. 2):

- изменялись процентные содержания биополимера, крахмала и каустической соды $(\mathrm{NaOH})$;

- был полностью исключен хлорид натрия в связи с тем, что концентрация соли в пластовой воде достаточна для поддержания требуемого уровня минерализации;

- применялся пеногаситель с целью устранения вспенивания промывочной жидкости;
- было принято решение удалить из рецептуры полианионную целлюлозу низкой и высокой вязкости, поскольку такие системы обладают достаточной загущающей способностью.

При этом нами было также отмечено, что:

- образцы буровых растворов на основе предоставленной промысловой химии и пластовой воды оказались нестабильны ввиду отрицательного влияния компонентов последней (в частности катионов металлов) [24];

- после непродолжительного времени происходило высаливание полимерных реагентов и потеря промывочной жидкостью всех реологических свойств (рисунок).

Это связано, прежде всего, с наличием в пластовой воде высокого содержания катионов $\mathrm{Ca}^{2+}$ и $\mathrm{Mg}^{2+}$, которые за счет своей высокой способности к гидратации уменьшают количество свободной воды, необходимой для растворения полимера, а также вступают в реакцию с последним [25].

Помимо всего, низкие значения водородного показателя $(\mathrm{pH}<5)$ отрицательно сказываются на растворении полимерных реагентов [26]. Так, например, согласно рекомендациям, для крахмала и биополимера оптимальными значениями являются $\mathrm{pH}=9-11$.

Для решения этого вопроса авторы попытались довести значения $\mathrm{pH}$ до требуемых путем увеличения концентрации $\mathrm{NaOH}$. Однако насыщенность раствора неорганическими солями, а именно $\mathrm{CaCl}_{2}$, позволило увеличить водородный показатель только до отметки, равной $\mathrm{pH}=7,5 \ldots 8,0$. При еще большем повышении концентрации щелочи происходит реакция образования осадка $\mathrm{Ca}(\mathrm{OH})_{2}$, который препятствует получению агрегативно- и седиментационно устойчивого бурового раствора с необходимыми параметрами.

Растворы на Даниловской воде получились более стабильными. Из анализа табл. 1 видно, что она менее минерализована и имеет значение $\mathrm{pH}=5,6$ и выше. При постепенном увеличении концентрации биополимера наблюдается рост реологических показателей и уменьшение водоотдачи раствора. 
Таблица 2. Состав и показатели буровых растворов на основе пластовой воды Даниловского НГКМ (проба № 1) $и$ Ичёдинского НМ (проба № 2)

Table 2. Composition and indicators of drilling fluids based on produced water from Danilovskoe oil and gas condensate field (sample no. 1) and Ichyodinskoe oil field (sample no. 2)

\begin{tabular}{|c|c|c|c|c|c|c|c|c|c|c|c|c|c|}
\hline \multirow{2}{*}{  } & \multicolumn{4}{|c|}{$\begin{array}{l}\text { Состав бурового } \\
\text { раствора, \% } \\
\text { Drilling mud } \\
\text { composition } \\
\end{array}$} & \multicolumn{8}{|c|}{$\begin{array}{c}\text { Показатели } \\
\text { Property }\end{array}$} & \multirow[b]{2}{*}{$\begin{array}{l}\text { Примечания } \\
\text { Notes }\end{array}$} \\
\hline &  &  & 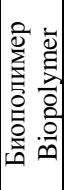 & 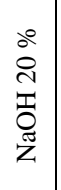 &  &  & 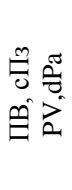 & 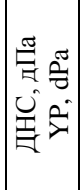 &  & 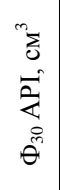 & $\begin{array}{l}\text { Корка } \\
\text { Crust }\end{array}$ & $\mathrm{pH}$ & \\
\hline 1 & 0,12 & 2,57 & 0,2 & 0,5 & 1,31 & 41,4 & 26,4 & 67,0 & $0,0 / 1,3$ & 4,6 & \multirow{3}{*}{$\begin{array}{c}\text { на пленке } \\
\text { комочки } \\
\text { Skin with lumps }\end{array}$} & 7,25 & $\begin{array}{l}\text { Полимер не растворился, аэрирован } \\
\text { Polymer was not dissolved, aerated }\end{array}$ \\
\hline 1 & 0,15 & 2,57 & 0,3 & 0,5 & 1,31 & 62,0 & 30,0 & 180,0 & $21,0 / 42,0$ & 3,2 & & 7,70 & $\begin{array}{l}\text { Полимер не растворился } \\
\text { Polymer was not dissolved }\end{array}$ \\
\hline 1 & 0,12 & 2,57 & 0,4 & 0,5 & 1,31 & $\mid 173,6$ & 36,8 & 341,0 & $48,0 / 65,0$ & 1,6 & & 7,60 & $\begin{array}{l}\text { Полимер не растворился } \\
\text { Polymer was not dissolved }\end{array}$ \\
\hline 1 & 1,7 & 2,57 & 0,4 & 0,5 & 1,25 & $\mid 148,0$ & 36,0 & 238,0 & $45,0 / 123,0$ & 1,8 & $\begin{array}{l}\text { Пленка } \\
\text { Skin }\end{array}$ & 7,49 & $\begin{array}{l}\text { Рассол разбавлен. Через } 24 \text { часа рас- } \\
\text { слоился } \\
\text { Brine is diluted. After } 24 \text { hours, it was } \\
\text { stratified }\end{array}$ \\
\hline 2 & 0,12 & 2,57 & 0,4 & 0,5 & 1,34 & 18,4 & 12,1 & 0 & $0 / 0$ & 23 & $\begin{array}{l}\text { Рыхлая } \\
\text { Friable skin }\end{array}$ & 7,28 & $\begin{array}{l}\text { Полимер не растворился, аэрирован, } \\
\text { через } 24 \text { часа расслоился } \\
\text { Polymer was not dissolved, aerated, } \\
\text { after } 24 \text { hours it was stratified }\end{array}$ \\
\hline 2 & 0,12 & 2,57 & 0,2 & 0,5 & 1,34 & 20,4 & 9,2 & 1,0 & $0 / 0$ & 55 & $\begin{array}{c}\text { толстый слой } \\
\text { рыхлой корки } \\
\text { thick layer of } \\
\text { friable crust }\end{array}$ & 7,30 & $\begin{array}{l}\text { В раствор добавлен } \mathrm{Na}_{2} \mathrm{CO}_{3} 0,18 \%, \\
\text { выпал белый твердый осадок, кото- } \\
\text { рый не растворился. } \\
0,18 \% \mathrm{Na}_{2} \mathrm{CO}_{3} \text { was added to the solu- } \\
\text { tion, a white solid precipitated which } \\
\text { was not dissolved }\end{array}$ \\
\hline 2 & \begin{tabular}{|l|}
0,12 \\
\end{tabular} & 2,57 & \begin{tabular}{|l|}
0,2 \\
\end{tabular} & 0,5 & 1,22 & 37,7 & 24,0 & 52,0 & $2,0 / 8,0$ & \begin{tabular}{|l|}
4,1 \\
\end{tabular} & \multirow{3}{*}{$\begin{array}{l}\text { Пленка } \\
\text { Skin }\end{array}$} & 8,16 & \multirow{3}{*}{$\begin{array}{l}\text { Рассол разбавлен. Однородный, ма- } \\
\text { ло аэрирован } \\
\text { Brine is diluted. Homogeneous, slight- } \\
\text { ly aerated }\end{array}$} \\
\hline 2 & \begin{tabular}{|l|}
0,12 \\
\end{tabular} & 2,57 & 0,3 & 0,5 & 1,22 & 47,6 & 27,5 & 73,0 & $7,0 / 16,0$ & 3,6 & & 8,00 & \\
\hline 2 & 0,15 & 2,57 & 0,4 & 0,5 & 1,22 & 63,6 & 32,3 & 108,0 & $13,0 / 25,0$ & 2,8 & & 8,02 & \\
\hline
\end{tabular}

Примечание: $\rho$ - плотность; УВ напряжение сдвига; CHC $_{10 / 10}$ - статическое напряжение сдвига (за 10 секунд и за 10 минут); $\Phi_{30}$ АРI - фильтрачия за 30 минут по АРI; $\mathrm{pH}$ - водородный показатель.

Notes: $\rho$-density; $F V_{200 / 100}$ - funnel viscosity; PV-plastic viscosity; $Y P$ - yieldpoint; GS - gelstrengths (for 10 seconds and 10 minutes); $F_{30} A P I$ - filtration for 30 minutes by API; $p H$ - hydrogen ion exponent.

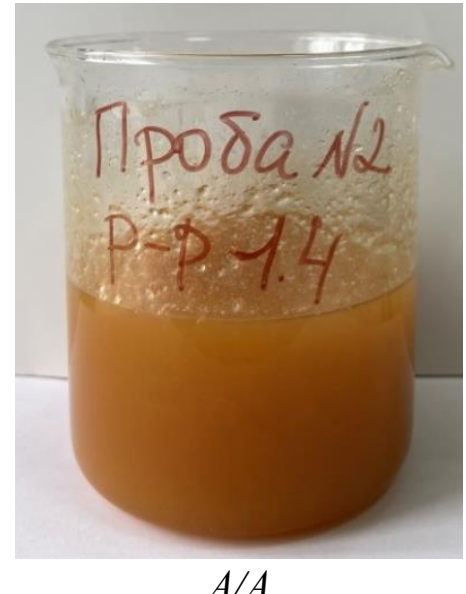

$A / A$

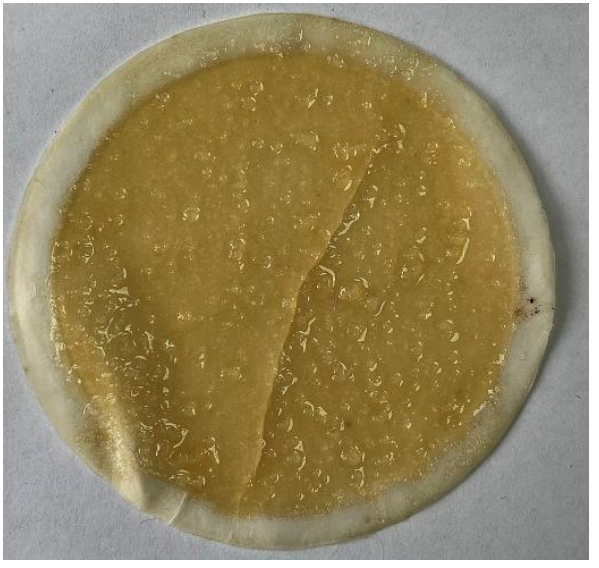

$5 / B$

Рисунок. Раствор на основе пластовой воды Даниловского месторождения (А) и полученная фильтрачионная корка (Б) Figure. Solution based on formation water of Danilovskoe field $(A)$ and the resulting filter cake $(B)$

Далее с целью снижения влияния солей было принято решение о разбавлении пластовой воды до необходимой плотности при бурении под техническую и эксплуатационную колонны [27]. Результаты данных исследований представлены в табл. 3. При этом репульпация происходила в соотношении «Вода/Рассол»=2/3 с сохранением необходимого уровня минерализации раствора. 
Таблица 3. Состав и показатели утяжеленных буровых растворов на основе пластовой воды Ичёдинского НМ (проба № 2)

Table 3. Composition and indicators of heavy drilling fluids based on produced water of Ichyodinskoe oil field (sample no. 2)

\begin{tabular}{|c|c|c|c|c|c|c|c|c|c|c|c|c|c|c|}
\hline \multirow[b]{2}{*}{$\begin{array}{c}\text { № пробы } \\
\text { Sample No. }\end{array}$} & \multicolumn{5}{|c|}{$\begin{array}{c}\text { Состав бурового раствора } \\
\text { № } 1, \% \\
\text { Drilling mud composition no. } 1\end{array}$} & \multicolumn{8}{|c|}{$\begin{array}{c}\text { Показатели } \\
\text { Properties }\end{array}$} & \multirow[b]{2}{*}{$\begin{array}{l}\text { Примечание } \\
\text { Notes }\end{array}$} \\
\hline &  & 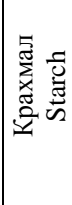 &  & $\begin{array}{l}\delta 0 \\
0 \\
\text { I } \\
\mathbb{1} \\
0 \\
\text { Z } \\
Z\end{array}$ & 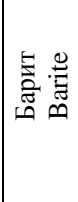 & $\begin{array}{l}0 \\
0 \\
0 \\
0 \\
0 \\
0 \\
0 \\
0 \\
0 \\
0 \\
0 \\
0 \\
0 \\
0 \\
0 \\
0\end{array}$ &  & 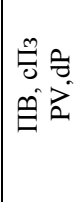 & 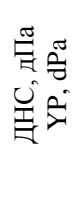 & 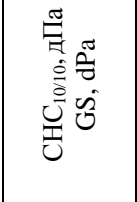 & 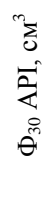 & 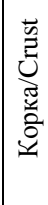 & $\frac{\pi}{2}$ & \\
\hline \begin{tabular}{|l|} 
до утяжеления \\
before weight
\end{tabular} & 0,2 & 2,57 & 0,4 & 0,5 & - & 1,22 & 70,4 & 31,9 & 114,0 & $15,0 / 34,0$ & - & - & 8,22 & aerated \\
\hline $\begin{array}{l}\begin{array}{l}\text { после утяжеления } \\
\text { after weight }\end{array} \\
\end{array}$ & 0,2 & 2,57 & 0,4 & 0,5 & 61,3 & 1,60 & 160,0 & 60,4 & 239,0 & $30,0 / 118,0$ & 1,1 & 2 & 8,23 & $\begin{array}{c}\text { суточный отстой } 5 \text { мл } \\
\text { daily sludge } 5 \mathrm{ml}\end{array}$ \\
\hline $\begin{array}{l}\text { до утяжеления } \\
\text { before weight }\end{array}$ & 0,2 & 2,57 & 0,4 & 0,5 & - & 1,22 & 71,0 & 31,2 & 105,0 & $16,0 / 32,0$ & - & - & 8,29 & - \\
\hline $\begin{array}{l}\begin{array}{l}\text { после утяжеления } \\
\text { after weight }\end{array} \\
\end{array}$ & 0,2 & 2,57 & 0,4 & 0,5 & 101,8 & 1,80 & 165,6 & 84,2 & 277,0 & $47,0 / 169,0$ & 1,4 & 2 & 8,15 & $\begin{array}{c}\text { суточный отстой } 3 \text { мл } \\
\text { daily sludge } 3 \mathrm{ml}\end{array}$ \\
\hline \begin{tabular}{|l|} 
до утяжеления \\
before weight \\
\end{tabular} & 0,2 & 2,57 & 0,4 & 0,5 & - & 1,22 & 70,8 & 31,2 & 105,0 & $16,0 / 32,0$ & - & - & 8,29 & - \\
\hline $\begin{array}{l}\text { после утяжеления } \\
\text { after weight }\end{array}$ & 0,2 & 2,57 & 0,4 & 0,5 & 150,0 & 2,02 & \begin{tabular}{|c|} 
Не течет \\
Doesn't \\
flow
\end{tabular} & 116,2 & 421,0 & $75,0 / 242,0$ & 2,8 & 2 & 8,07 & $\begin{array}{l}\text { суточный отстой } \\
4,5 \text { мл } \\
\text { daily sludge } 4,5 \mathrm{ml} \\
\end{array}$ \\
\hline
\end{tabular}

Примечание: УВ CHC ${ }_{10 / 10}$ - статическое напряжение сдвига (за 10 секунд и за 10 минут); $\Phi_{30}$ API - фильтрация за 30 минут по API; рH - водородньй показатель.

Notes: $F V_{200 / 100}$ - funnel viscosity; PV-plastic viscosity; YP - yieldpoint; GS - gelstrengths (for 10 seconds and 10 minutes); $F_{30} A P I-$ filtration for 30 minutes by API; $p H$ - hydrogen ion exponent.

Опытным путем нами установлено, что промывочные жидкости на основе разведенной Ичёдинской воды однородны, со стабильными показателями. Снизив её минерализацию разбавлением, мы получили возможность регулировать реологические и фильтрационные свойства растворов. По прошествии времени они оставались седиментационно устойчивыми и не подвергались бактериальному разложению.

Кроме того, особенностью данных составов также являются низкие значения водоотдачи, что очень важно при проводке скважин в соленосных горизон$\operatorname{Tax}[28]$.

В дальнейшем авторами на базе разбавленной пластовой воды были получены промывочные жидкости

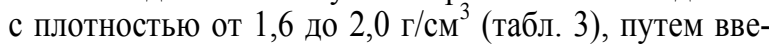
дения в них барита. При этом для предотвращения его выпадения в осадок очистные агенты предварительно обрабатывались полимерами.

Несмотря на высокое содержание утяжелителя, растворы обладают хорошей текучестью и стабильностью. Такие составы растворов позволяют корректировать свои свойства в сторону сокращения концентрации исходных компонентов, и их можно эффективно использовать при проявлениях рапы различной минерализации, в том числе и с аномально высоким пластовым давлением.

Вместе с тем альтернативой минерализованным растворам являются промывочные жидкости с конденсированной твердой фазой (гидрогель магния). Для получения гидрогеля магния из пластовой воды необходимо, чтобы в ее составе содержались ионы магния $\mathrm{Mg}^{2+}$ в количестве 10-40 г/л [6]. Теоретически данная система раствора может быть использована для бурения соленасыщенных отложений, высоконапорных, содержащих рапу горизонтов, а также при глушении и консервации скважин.

В результате проведённых лабораторных исследований было подтверждено, что высокоминерализованные пластовые воды, содержащие 12,5...13,2 г/л ионов магния после обработки $1,5 \ldots 2,0 \%$ раствором $\mathrm{NaOH}$ в виде 20-40\% концентрации при интенсивном перемешивании в турбулентном режиме переходят в структурированную систему - гидрогель магния Полученные растворы имеют высокую седиментационную устойчивость, повышенные смазочные свойства и обладают высокой утяжеляющей способностью.

Согласно предварительным расчетам, на указанных месторождениях внедрение промывочных жидкостей на основе пластовых вод позволит уменьшить затраты на строительство скважин.

В настоящее время работы в направлении совершенствования рецептур буровых растворов на основе пластовых вод нами продолжаются уже с использованием новых методик и химических реагентов.

\section{Выводы}

Изложенный выше обзорный и экспериментальный материал позволяет авторам сформулировать следующие заключения.

1. Использование пластовых вод в качестве дисперсионной среды для приготовления промывочных жидкостей при строительстве скважин на объектах ООО «ИНК-Сервис» позволит создать эффективную альтернативную систему их базовым аналогам (табл. 4). 
Таблица 4. Сравнение полимерных соленасыщенных растворов

Table 4. Comparison of polymer saline solutions

\begin{tabular}{|c|c|c|}
\hline \multirow[b]{2}{*}{$\begin{array}{l}\text { Параметр } \\
\text { Property }\end{array}$} & \multicolumn{2}{|c|}{ Значение/Value } \\
\hline & $\begin{array}{c}\text { Применяемый полимерный } \\
\text { соленасыщенный буровой растворов } \\
\text { Used polymer salt saturated drilling fluids }\end{array}$ & $\begin{array}{c}\text { Раствор на основе рассола } \\
\text { Ичёдинского месторождения } \\
\text { Drilling fluid based on brine Ichedinskoe field }\end{array}$ \\
\hline $\begin{array}{l}\text { Плотность } \rho, \Gamma / \mathrm{cm}^{3} \\
\text { Density } \rho, \mathrm{g} / \mathrm{cm}^{3} \\
\end{array}$ & $1,20 \ldots 1,25$ & 1,22 \\
\hline $\begin{array}{l}\mathrm{YB}_{200 / 100}, \mathrm{c} \\
\mathrm{FV}, \mathrm{s}\end{array}$ & $45-50$ & 65 \\
\hline $\begin{array}{l}\text { Водородный показатель } \\
\text { (hydrogen ion exponent), pH }\end{array}$ & $8-10$ & 8 \\
\hline ПВ мПа*с/PV, mPa*s & $\leq 30$ & 27,7 \\
\hline ДНС, дПа/ҮР, dPa & $\geq 70$ & 117,0 \\
\hline $\begin{array}{l}\text { CHC, дПа } 10 \text { сек } / 10 \text { мин } \\
\text { GS, dPa } 10 \mathrm{sec} / 10 \mathrm{~min}\end{array}$ & $\geq 24 / \geq 38$ & $\begin{array}{c}19 / 31 \\
\text { (после суточного отстоя (after daily sediment) 27/51) }\end{array}$ \\
\hline $\begin{array}{l}\Phi_{30} \text { API, } \mathrm{cm}^{3} / 30 \mathrm{Mин} \\
\mathrm{F}_{30} \mathrm{API}, \mathrm{cm}^{3} / 30 \mathrm{~min}\end{array}$ & $\leq 4$ & 2,8 \\
\hline
\end{tabular}

2. Содержание в пластовой воде в достаточном количестве магния $(\geq 10$ г/л) гарантирует получение гидрогель-магниевых буровых растворов.

3. Высокая минерализация, большое содержание $\mathrm{Ca}^{2+}$ и $\mathrm{Mg}^{2+}$, а также низкие значения показателя $\mathrm{pH}$ пластовых вод не дают возможности растворяться полимерным реагентам в полном объеме. Поэтому эффективным решением по созданию на их базе бурового раствора является разбавление пластовых вод, с целью изменения и регулирования его свойств.

4. Применение попутных пластовых вод позволит снизить материальные и временные затраты, свя-

\section{СПИСОК ЛИТЕРАТУРЫ}

1. Елимова В.В. Рассолы ярактинской группы месторождений // Строение литосферы и геодинамика: Материалы XXVII Bceроссийской молодежной конференции с участием исследователей других стран. - Иркутск: Институт земной коры Сибирского отделения РАН, 2017. - С. 87-88.

2. Вахромеев А.Г. Закономерности формирования и концепция освоения промышленных рассолов (на примере юга Сибирской платформы): автореф. дис. ... д-ра геол.-минерал. наук. Иркутск, 2009. - 380 с.

3. Хайловский В.Н., Тинакина Л.В., Луханина И.В. Выявление особенностей сульфатно-терригенных пропластков в соленосных отложениях нижней перми Астраханского свода // Международный научно-исследовательский журнал. - 2015. T. 37. - № 6-2. - C. 47-53.

4. Fink J.K. Petroleum engineer's guide to oil field chemicals and fluids. - Waltham, MA: Gulf Professional Publ., 2011. - 808 p.

5. Caenn R., Chillingar G.V. Drilling fluids: state of the art // Journal of Petroleum Science and Engineering - 1996. - V. 14. - Iss. 3-4. P. 221-230.

6. Ангелопуло О.К., Подгорнов В.М., Аваков В.Э. Буровые растворы для осложненных условий. - М.: Недра, 1998. - 135 с.

7. Samira Baba Hamed, Mansour Belhadri. Rheological properties of biopolymers drilling fluids // Journal of Petroleum Science and Engineering. - 2009. - V. 67. - Iss. 3. - P. 84-90.

8. Jones T.G.J., Hughes T.L. Drilling fluid suspensions // Suspensions: fundamentals and applications in the petroleum industry. - 1996. - V. 251. - Iss. 10. - P. 463-564.

9. Ланина Т.Д. Использование пластовых вод в качестве технологической жидкости для приготовления буровых растворов и консервации скважин // Строительство нефтяных и газовых скважин на суше и море. - 2007. - № 12. - С. 29-32.

10. Быков И.Ю., Ланина Т.Д., Комиссарова Е.С. Буровые растворы на основе гидрогеля магния из пластовых вод // Строительство нефтяных и газовых скважин на суше и море. 2010. - № 9. - C. 44-47. занные с насыщением раствора солями на поверхности, одновременно предупредить кавернообразования и в значительной степени предотвратить осложнения при проводке скважин в условиях бурения хемогенных пород (каменная соль с переслаиваниями доломитов, доломито-ангидритов и известняков).

Авторы благодарят компании ООО «Иркутская нефтяная компания» и ООО «ИНК-Сервис» за проявленный интерес в развитии исследований, в частности руководителя проекта «Рассолы» ИНК Евгения Чертовских.

11. Буровой раствор: пат. Рос. Федерация, № 2119520, заявл. 01.02.1996; опубл. 27.09.1998, Бюл. № 27. - 10 c.

12. Модифицированная оксиэтилцеллюлоза и буровые растворы на ее основе / И.М. Тимохин, В.Н. Тесленко, А.А. Русаев, В.А. Русаев // Геология, геофизика и разработка нефтяных и газовых месторождений. - 2000. - № 12. - С. 53-56.

13. Буровой раствор на основе природного рассола / В.В. Казанский, О.Б. Сукманский, О.А. Брагина, В.В. Дорохова, В.П. Низовцев // Нефтяное хозяйство. - 1998. - № 11. - С. 8-10.

14. Реагент для обработки высокоминерализованного бурового раствора: пат. Рос. Федерация, № 2084487, заявл. 08.11.1994; опубл. 20.07.1997. Бюл. № 20. - 6 с.

15. Реагент для обработки высокоминерализованного бурового раствора: пат. Рос. Федерация № 2213122, заявл. 19.11.2001; опубл. 27.09.2003. Бюл. № 27. - 6 c.

16. Буровой раствор: пат. СССР № 1090700, заявл. 15.09.1981, опубл. 07.05.1984. Бюл. 13. $-3 \mathrm{c}$.

17. Averkina E.V., Shakirova E.V. Specifics of drilling wells in the abnormally-high-pressure rock beds in the oil-and-gas fields of Eastern Siberia // Prospects Mining and Metallurgy Industry Development. IOP Conf. Series: Earth and Environmental Science. - 2019. - № 229. - P. 1-5.

18. Caenn R., Darley H.C.H, Gray G. Composition and properties of drilling and completion fluids. - Cambridge, MA: Gulf Professional Publ., 2017. - 729 p.

19. ГОСТ 33213-2014 (ISO 10414-1:2008). Контроль параметров буровых растворов в промысловых условиях. Растворы на водной основе. - М.: Стандартинформ, 2015. -75 с.

20. РД 39-00147001-773-2004. Методика контроля параметров буровых растворов. - Краснодар: ОАО НПО «Бурение». -45 с.

21. ГОСТ Р 56946-2016 (ISO 13500:2008). Нефтяная и газовая промышленность. Материалы буровых растворов. Технические условия и испытания. - М.: Стандартинформ, 2016. $105 \mathrm{c}$.

22. Xie W., Lecourtier J. Xanthan behaviour in water-based drilling fluids // Polymer Degradation and stability. - 1992. - V. 38. P. $155-164$. 
23. Akpan E.U., Enyi G.C., Nasr G.G. Enhancing the performance of xanthan gum in water-based mud systems using an environmentally friendly biopolymer // Journal of Petroleum Exploration and Production Technology. - 2020. - V. 10. P. 1933-1948.

24. Rheological characterisation of xanthan gum in brine solutions at high temperature / D. Reinoso, M.J. Martin-Alfonso, P.F. Luckham, F.J. Martinez-Boza // Carbohydrate Polymers. 2018. - V. 203. - P. 103-109.

25. Аксенова Н.П., Рожкова О.В. Буровые промывочные жидкости и промывка скважин. В 3 т. Т. 2. - Тюмень: Изд-во ТИУ, 2016. $-102 \mathrm{c}$.
26. Kelly J. Drilling fluid selection, performance and quality control // Society of Petroleum Engineers. - 1983. - V. 35. - Iss. 05. P. 889-899.

27. Устюжанин А.О. Исследование, разработка буровых растворов на основе подземных вод месторождений Восточной Сибири // Всероссийская молодежная научно-практическая конференция нефтегазовой отрасли. - Красноярск: Сибирский федеральный университет, 2019. - С. 18-19.

28. Applied drilling engineering / A.T. Bourgoyne Jr., K.K. Millheim, M.E. Chenevert, F.S. Young Jr. - Texas, SPE Richardson, 1986. V. 2. $-502 \mathrm{p}$.

Поступила 01.03.2021 г.

\section{Информация об авторах}

Буглов Н.A., кандидат технических наук, заведующий кафедрой нефтегазового дела, Иркутский национальный исследовательский технический университет.

Аверкина E.B., старший преподаватель кафедры нефтегазового дела, Иркутский национальный исследовательский технический университет.

Устюжанин A.O., магистрант Института высоких технологий, Иркутский национальный исследовательский технический университет.

Красинская А.C., ведущий инженер по растворам ООО «ИНК-СЕРВИС». 
UDC 622.24 .06

\title{
RESEARCH OF BIOPOLYMER DRILLING FLUIDS BASED ON HIGHLY MINERALIZED RESERVOIR WATERS OF EASTERN SIBERIA
}

\author{
Nikolay A. Buglov' \\ bna@istu.edu \\ Elena V. Averkina ${ }^{1}$, \\ averkina.|@yandex.ru
}

Aleksandr O. Ustyuzhanin ${ }^{1}$, al.ust7@yandex.ru

\author{
Anastasia S. Krasinskaya², \\ krasinskayaas@irkutskoil.ru \\ 1 Irkutsk National Research Technical University, \\ 83, Lermontov street, Irkutsk, 664074, Russia. \\ 2 INK-Service, \\ 24A, Oktyabrskoy revolyutsii street, Irkutsk, 664007, Russia.
}

The relevance of the research is caused by the need for the beneficial use of formation water, produced simultaneously with oil, as the basis for preparing highly mineralized drilling fluids when drilling in fields in Eastern Siberia.

The main aim of the research is to study and propose polymer systems of drilling fluids based on formation waters of Eastern Siberia.

Objects: formation water of the Danilovskoe and Ichedinskoe oil and gas condensate fields, formulations and components of modern polymer drilling fluid systems.

Methods: instrumental methods for determining drilling muds parameters according to State Standard 33213-2014 and guidance document RD 39-00147001-773-2004 (filtration and rheological properties); description of samples, comparison of characteristics with similar solutions.

Results. The authors have studied and described the physicochemical characteristics of formation water; prepared polymer systems of drilling fluids based on pure and diluted formation water; carried out comparative studies of the prepared solutions with the solutions currently used in the construction of wells in Eastern Siberia. Descriptive characteristics of drilling solutions and theories on the interaction of the used reagents with formation water are presented. It was found that due to the high content of calcium and magnesium chlorides in the formation water, the process of dissolving polymer reagents can be suspended, which leads to a complete loss of all the viscosity, filtration and rheological properties of drilling fluids; a sufficient amount of magnesium in the produced water ( $\geq 10 \mathrm{~g} / \mathrm{l})$ ensures that hydrogelmagnesium drilling fluids obtaining; the use of associated formation water will reduce material and time costs associated with saturation of the solution on the surface, at the same time prevent cavern formation and to a large extent prevent the solubility of saline rocks.

\section{Key words:}

Formation water, hydromineral raw materials, mineralization, drilling mud, saline drilling mud, Yarakta field, drilling fluid, Eastern Siberia.

The authors are grateful to the "Irkutsk Oil Company» LLC and the «INC-Service» LLC for their interest in the development of research, in particular to Evgeny Chertovskikh, the leader of the INK's project «Rassoly».

\section{REFERENCES}

1. Elimova V.V. Rassoly yaraktinsloy gruppy mestorozhdeny [Brines of the Yarakta group of deposits]. Stroenie litosfery i geodinamika. Materialy XXVII Vserossiyskoy molodezhnoy konferentsii s uchastiem issledovateley grugikh stran [The structure of the lithosphere and geodynamics. Materials of the XXVII All-Russian Youth Conference with the participation of researchers from other countries]. Irkutsk, Institute of the Earth's Crust, Siberian Branch of the Russian Academy of Sciences, 2017. pp. 87-88.

2. Vakhromeev A.G Zakonomernosti formirovaniya i kontseptsiya osvoeniya promyshlennykh rassolov (na primere yuga Sibirskoy platformy). Avtoreferat Dis. Dokt. nauk [Patterns of formation and the concept of development of industrial brines (on the example of the south of the Siberian platform)]. Irkutsk, 2009. $380 \mathrm{p}$.

3. Khailovsky V.N., Tinakina L.V., Lukhanina I.V. Revealing the features of sulfate-terrigenous interlayers in salt-bearing sediments of the Lower Permian of the Astrakhan arc. International scientific research journal, 2015, vol. 37, Iss. 6-2, pp. 47-53. In Rus.

4. Fink J.K. Petroleum engineer's guide to oil field chemicals and fluids. Waltham, MA, Gulf Professional Publ., 2011. 808 p.
5. Caenn R., Chillingar G.V. Drilling fluids: state of the art. Journal of Petroleum Science and Engineering, 1996, vol. 14, Iss. 3-4, pp. 221-230.

6. Angelopulo O.K., Podgornov V.M., Avakov V.E. Burovye rastvory dlya oslozhnennykh usloviy [Drilling fluids for difficult conditions]. Moscow, Nedra Publ., 1998. 135 p.

7. Samira Baba Hamed, Mansour Belhadri. Rheological properties of biopolymers drilling fluids. Journal of Petroleum Science and Engineering, 2009, vol. 67, Iss. 3, pp. 84-90.

8. Jones T.G.J., Hughes T.L. Drilling fluid suspensions. Suspensions: Fundamentals and Applications in the Petroleum Industry, 1996, vol. 251, Iss. 10, pp. 463-564.

9. Lanina T.D. The use of reservoir water as a process fluid for the preparation of drilling fluids and conservation of wells. Construction of oil and gas wells on land and sea, 2007, no. 12, pp. 29-32. In Rus.

10. Bykov I.Y., Lanina T.D., Komissarova E.S. Drilling fluids based on magnesium hydrogel from reservoir waters. Construction of oil and gas wells on land and sea, 2010, no. 9, pp. 44-47. In Rus.

11. Galyan D.A., Chadina N.P., Igoshkin V.I., Nechaeva A.K. Burovoy rastvor [Drilling mud]. Patent RF, no. 2119520, 1998. 
12. Timokhin I.M., Teslenko V.N., Rusaev A.A., Rusaev V.A. Modified oxoethyl cellulose and drilling fluids based on it. Geology, geophysics and development of oil and gas fields, 2000, no. 12, pp. 53-56. In Rus.

13. Kazansky V.V., Sukmansky O.B., Bragina O.A., Dorokhova V.V., Nizovtsev V.P. Drilling fluid based on natural brine. Oil Industry, 1998, no. 11, pp. 8-10. In Rus.

14. Kazansky V.V., Sukmansky O.B., Bragina O.A., Dorokhova V.V., Nizovtsev V.P. Reagent dlya obrabotki vysokomineralizovannogo burovogo rastvora [Reagent for processing highly mineralized drilling mud]. Patent RF, no. 2084487, 1997.

15. Abrams L.A., Sukmansky O.B., Bragina O.A. Reagent dlya obrabotki vysokomineralizovannogo burovogo rastvora [Reagent for processing highly mineralized drilling mud]. Patent RF, no. 2213122,2003 .

16. Klimashkin I.I., Polyakov G.A., Khashimov M.Kh., Mamadzhanov U.D., Khodzhaeva M.G. Burovoy rastvor [Drilling mud]. Patent USSR, no. 1090700, 1984.

17. Averkina E. V., Shakirova E.V. Specifics of drilling wells in the abnormally-high-pressure rock beds in the oil-and-gas fields of Eastern Siberia. Prospects Mining and Metallurgy Industry Development. IOP Conf. Series. Earth and Environmental Science, 2019 no. 229 , pp. $1-5$.

18. Caenn R., Darley H.C.H, Gray G. Composition and properties of drilling and completion fluids. Cambridge, MA, Gulf Professional Publ., 2017. $729 \mathrm{p}$.

19. GOST 33213-2014 (ISO 10414-1:2008). Kontrol parametrov burovykh rastvorov v promyslovykh usloviyakh. Rastvory na vodnoy osnove [State Standard 33213-2014 (ISO 10414-1:2008). Field testing of drilling fluids. Water-based fluid]. Moscow, Standartinform Publ., 2015. $75 \mathrm{p}$.

20. RD 39-00147001-773-2004. Metodika kontrolya parametrov burovykh rastvorov [Guidance document 39-00147001-773-2004. Methods for controlling the parameters of drilling fluids]. Krasnodar, JSC NPO Burenie Pabl., 2004. 45 p.
21. GOST R 56946-2016 (ISO 13500:2008). Neftyanaya i gazovaya promyshlennost. Materialy burovykh rastvorov. Tekhnicheskie usloviya $i$ ispytaniya [State Standard 56946-2016 (ISO 13500:2008). Petroleum and natural gas industries. Drilling fluid materials. Specifications and tests]. Moscow, Standartinform Publ., 2016. $105 \mathrm{p}$

22. Xie W., Lecourtier J. Xanthan behaviour in water-based drilling fluids. Polymer Degradation and stability, 1992, vol. 38, Iss. 2, pp. 155-164.

23. Akpan E.U., Enyi G.C., Nasr G.G. Enhancing the performance of xanthan gum in water-based mud systems using an environmentally friendly biopolymer. Journal of Petroleum Exploration and Production Technology, 2020, vol. 10, pp. 1933-1948.

24. Reinoso D., Martin-Alfonso M.J., Luckham P.F., MartinezBoza F.J. Rheological characterisation of xanthan gum in brine solutions at high temperature. Carbohydrate Polymers, 2018, vol. 203, pp. 103-109.

25. Aksenova N.P., Rozhkova O.V. Burovye promyvochnye zhidkosti $i$ promyvka skvazhin [Drilling washing liquid and washing of wells]. Tyumen, TIA Publ., 2016. Vol. 2, Iss. 3, 102 p.

26. Kelly J. Drilling fluid selection, performance and quality control. Society of Petroleum Engineers, 1983, vol. 35, Iss. 05, pp. 889-899.

27. Ustyuzhanin A.O. Issledovanie, razrabotka burovykh rastvorov na osnove podzemnykh vod mestorozhdeniy Vostochnoy Sibiri [Research, development of drilling fluids based on groundwater from fields in Eastern Siberia]. Vserossiyskaya molodezhnaya nauchnoprakticheskaya konferentsiya neftegazovoy otrasli [All-Russian Youth Scientific and Practical Conference of the Oil and Gas Industry]. Krasnoyarsk, Siberian Federal University Publ., 2019. pp. 18-19.

28. Bourgoyne Jr. A.T., Millheim K.K., Chenevert M.E., Young Jr. F.S. Applied drilling engineering. Texas, SPE Richardson, 1986. Vol. 2, $502 \mathrm{p}$.

Received: 1 March 2021.

\section{Information about the authors}

Nikolay A. Buglov, Cand. Sc., head of the Department of Oil and Gas, Irkutsk National Research Technical University. Elena V. Averkina, senior lecturer, Irkutsk National Research Technical University.

Aleksandr O. Ustiuzhanin, master student, Irkutsk National Research Technical University.

Anastasia S. Krasinskaya, leading engineer of drilling fluids, INK-Service. 